\title{
Metaphor of Diseases in Contemporary European Paintings
}

\author{
Xiaonan Fan \\ Tsinghua University \\ Beijing, China \\ Tianjin Fine Arts Institute \\ Tianjin, China
}

\begin{abstract}
Diseases, which are the dark side of life, are all the time taken as the metaphors of death, human weakness and fragility per se. Each citizen has double identities as health and disease. In addition, how these diseases are met aphorized step by step transferring to a standard of morals and political attitude from nothing but a part of body? The contemporary European painters constantly present the diseased human bodies through various art languages, obviously, the diseased bodies per se are not what they actually concern, but the usage of taking diseases as a rhetorical device or metaphor is. In virtue of paints, they reveal the dissimilation to human made by diseases in contemporary society, confront and deep touch the source of diseases, which express the artists' concerns and reflections on realistic situation of human society.
\end{abstract}

Keywords—diseases; metaphor; politics; modernity

\section{INTRODUCTION}

Diseases, which are the dark side of life, are all the time taken as the metaphors of death, human weakness and fragility per se. Each citizen has double identities as health and disease. How these diseases are met aphorized step by step transferring to a standard of morals and political attitude from nothing but a part of body or how a kind of disease metaphor transfer to another? The tuberculosis is a kind of romantic disease with nobility character, while cancer and stroke diseases become bourgeois diseases, it seems that the diseases also have class characters and different aesthetics grades. However, only in the aesthetics and moral categories still dissatisfy thus disease metaphor, it frequently enters to politics and race categories, which has become a vivid rhetoric weapon to deal with dissidents at domestic and overseas or opposition factions.

The contemporary European painters constantly present the diseased human bodies through various art languages, obviously, the diseased bodies per se are not what they actually concern, but the usage of taking diseases as a rhetorical device or metaphor is (metaphor refer to take the place of one by other one's name, and the split between phenomenon and essence also). These pictures of paintings are distinguish from other ones produced by the society of spectacle, and the artists repair the sham pictures in digital time with metaphors of diseases, which further get rid of the dissimilation to human given by the society diseases while revealing and presenting these metaphors.

\section{Multi-MetAPHOR OF DisEASES}

Various diseases exist in human society, and all kinds of new style are derived with the living environment's deterioration, which come fiercely and most of them are infectious diseases that could lead the mass mortality of human, from what, the scope and connotation of metaphor of diseases evolve and deepen unceasingly. he diseases, cancer, tuberculosis, syphilis, flu, Aids and pestilence diseases, are frequently referred in formerly metaphors, the reason, people, symptom and order of severity of which are used to evolve the diseases into the categories of metaphor, and applied corresponding to multi-aspects of human's mentality, aesthetic, politics and culture in different period.

Luc Tuyman has a keen understanding of metaphor of diseases, in his ten series of works of Diagnose View "Fig. 1", which take the diagnose pictures of diagnose manual as reference, he intensively presents the metaphors of diseases. These works present strong visual effect under the medical floodlights, when facing at them, the viewers cannot help asking where these diseases come from, or whether we have such diseases as well. It is a part feature of a single breast in Diagnose View VII "Fig. 2, we can see clearly the lesion and ragged parts of the breast, which bring in our mind the cut part of the malignancy immediately, as if this breast has separated from the body leaving the heaviness and potential pain in the viewers' hearts. And another is a tumor feature of skin cancer in Diagnose View X "Fig. 3", the tumor is nagger-brown with viscous yellow liquid surrounding, due to the flesh pink background we cannot distinguish whether it had been excised or not. The digital " 10 " marked clearly on the top right corner of the picture is directly connected with the tumor, is it the tenth tumor, or it represent the order of severity of the lesion, or it is the category code of tumor? However, these questions seem to be unimportant due to any information about tumor is pointing to death. 


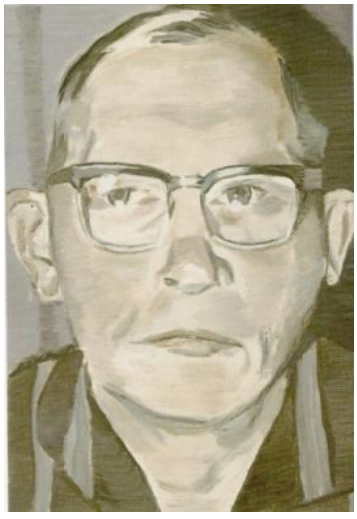

Fig. 1. Diagnose View II, Luc Tuymans 1992

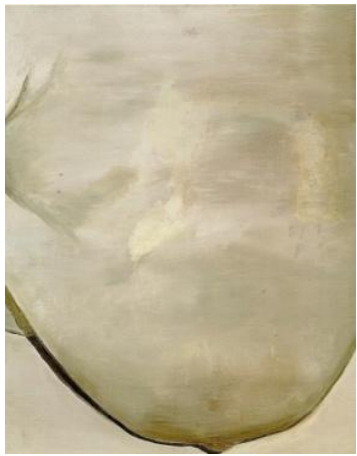

Fig. 2. Diagnose View VII, Luc Tuymans 1992

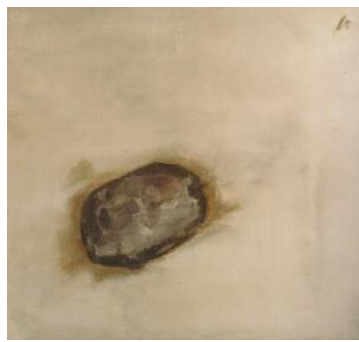

Fig. 3. Diagnose View X, Luc Tuymans 1992

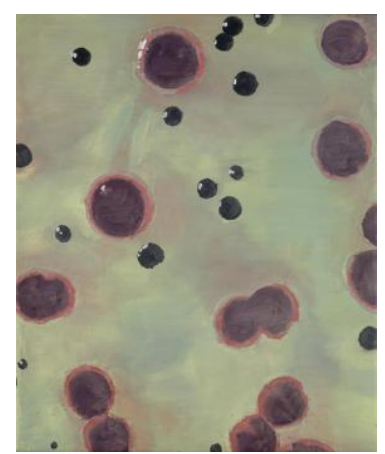

Fig. 4. BIoodstain, Luc Tuymans 1993

Nothing is more punitive than giving diseases the meaning of morality. The metaphor of Aids is taken as free sex distinguishing from the cancer, which bring the social death sooner than physical death. The works Bloodstain emerges an amplifying blood cell under the microscope "Fig. 4", through the floating abstract picture brings the viewers a shudder of horror.
Luc Tuymans made concrete cells turn to be osmotic abstract pattern by using the zoom lens, we should believe that it must be diseased blood. Once Luc Tuymans was asked that whether the blood hint at Aids, he denied, but acquiesced "maybe there is some subconscious relationship".

In a large amount of works of Marlene Dumars, the attention and depict about diseases are nothing new, like Albinism, Yellows and Painter and other works carrying out the profoundly experience and observe to human predicament. "Fig. 5"

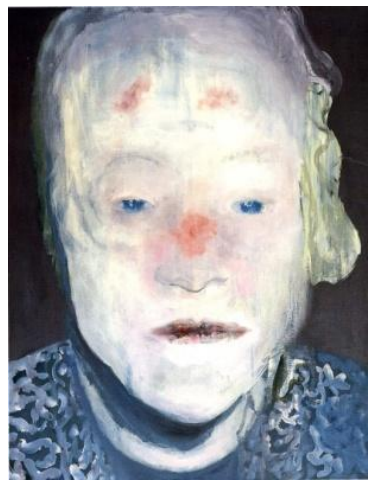

Fig. 5. Albinism, Marlene Dumas 1985

Albinism (1985) is referred to a postcard that has three pictures of patients' lesion "Fig. 6". The diseased old man, whose pale face oozed orange mottled trails, black red lips just as the sere blood, sparse yellow hair revealed the severity of his state of illness, all seems that his disease is not curable and he would soon be leaving the world. Albinism (1986) showed a black man but got albinism "Fig. 7", facing which showing the contradiction and conflict, Dumas obviously was not just describing the disease per se. Dumas is a white woman born in South Africa, the racial problem was what she cannot avoid and made her feel a deep hurt. The painter through the metaphor of diseases makes the contradiction and conflict between whites and blacks become more shocking by the sight. The woman in the Sad Romy was not just a matter of heart-broken "Fig. 8", her filemot face, yellow green forehead and the splotch-like flowing muddy pigment, seem to reveal the skin fester and obviously is a omen of diseases. Whether it is the emotion's repression leading to the spread of diseases.

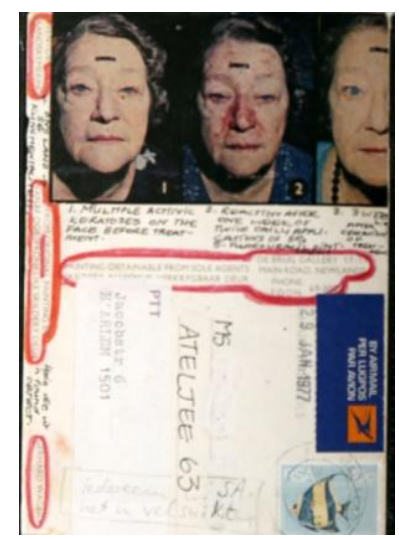

Fig. 6. The postcard referred for Albinism 


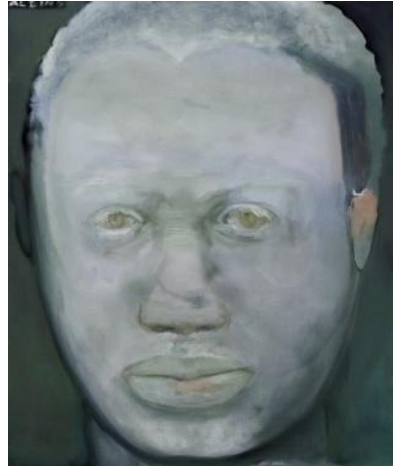

Fig. 7. Albinism, Marlene Dumas 1986

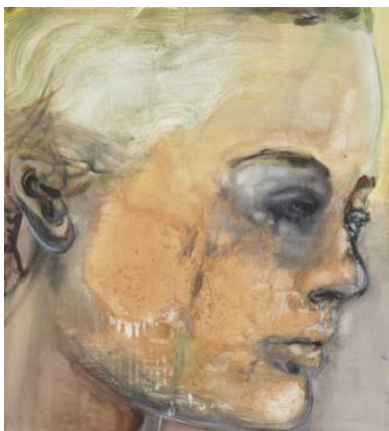

Fig. 8. The sad Romy, Marlene Dumas 1985

The works of Romania painter Adrian Ghenie, is involving the theme of diseases as well, the figures in which, both men and women, all seemed to get elephantiasis, disfiguring faces, peeled portraits etc. horrifying pains are overflowing with the pictures. His works are referred to the screenshot of the US comedy the Three Stooges in 1941 "Fig. 9", which represents people playing war game by pies, from which we can see that Ghenie depicted figures only with flesh color and the actual color of pie in his early works in 2008. While after 2012, the figures and color had great change, that the comedian was changed to other figure and the color of his works added subjectivity color of blood and cyanosis of skin as well. The painter gives his works a more specific meaning direction. The Indoor of Pie Fight depicts is Hitler's wife Eva Braun and Portrait of Darwin depicts the author of theory of evolution Darwin "Fig. 10" "Fig. 11", whose face is disfigured in the work, showing the artist's deep query on the theory of evolution. The image of Hitler in No Title is scraped and coated by red color "Fig. 12". The morbidity effect comes from the destruction and reshape to the figure's face did by Ghenie in the face of unbearable memories history, gives the metaphor of human war and sin.

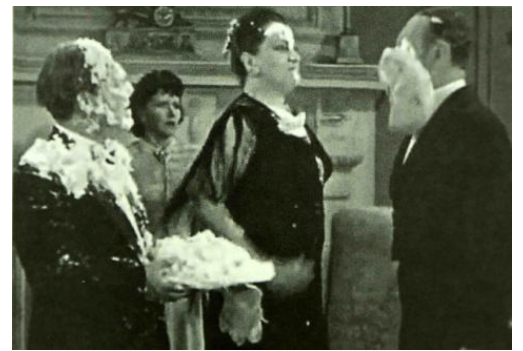

Fig. 9. The screenshot of the comedy movie The Three Stooges, 1941

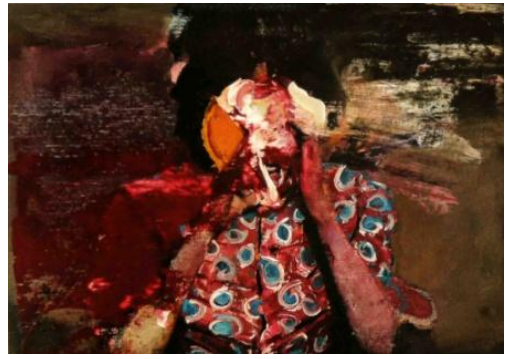

Fig. 10. Indoor of Pie Fight, Adrian Ghenie 2012

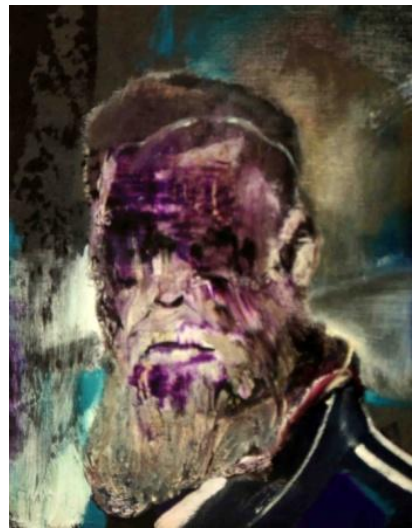

Fig. 11. Portrait of Darwin, Adrian Ghenie 2012

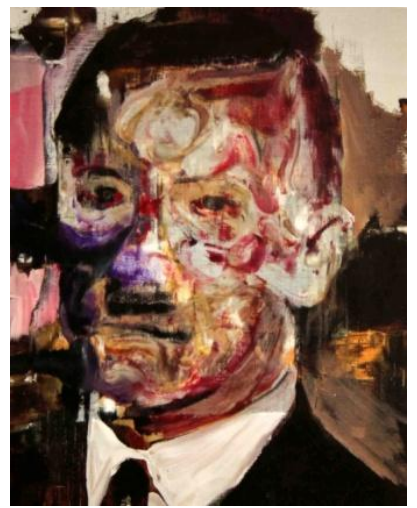

Fig. 12. No Title, Adrian Garnier 2011

A large amount of metaphors of diseases appeared from European painters' works are not coincidence, facing the history and reality, artists wish to express their attitude to the society through painting, hence the expression and depiction of kinds of human diseases are found and used by them and with the representation of various symptom characteristics they give more metaphorical meaning to art works. Through these works, contemporary painters strive to reveal the large defection in our culture, our avoiding attitude to death, the weakness of our proper renounce consumption's development of developed industrial society, our anxiety to emotion and furthermore the fear to increasing capable of violence in course of history.

\section{Metaphor OF Diseases AND Political Philosophy}

Metaphor of diseases make the ideal of a sane society clear, which's analogy is taken as physical health, the ideal usually 
has anti-political complexion, but also is a appeal for a new political order. The order is the earliest concerned thing of political philosophy, while city-state is always taken as organism, so take the national disorder as diseases is naturally logical. Diseases originate from out-of-balance, the aim of treatment is to recover the normal equilibrium, in political words, to recover the normal hierarchy. In political philosophy's mainstream tradition, to take an analogy of national order to diseases is to urge governors to pursue policy that is more rational. While European artists mould kinds of diseased bodies, blend their metaphors and thoughts about political structure of state condition in the pictures, making the works be with infinite profound meaning and reference space, hence, the style of drawing and color also have more abundant meanings.

The Evil Mediocrity quotes the view of famous ideologist Hannah Arendt of 20th century who put forward the "evil mediocrity" in allusion to the judgment of Eichmann made by anti-Semitism "Fig. 13". And Dumas drew a portrait of herself, inversely sitting on the chair with her hands on the back of it, her pale face and red orbit looks rather striking. Her hand is on the front of the picture while covered with a black layer as syphiloderm extend to her whole body. Moreover, the left part of her face also turns to be black green and permeates bloodlike red color; her lemon yellow lip has to be the symptom of diseases, as well as her hair with color of jacinth and black splodge renders the tense atmosphere extremely. In Desire for Evolution "Fig. 14", the red yellow body is in stark contrast to the black green face and background. The fresh red color on the head of the figure extends all the way to neck and breast, like blood or flaming fire in her body. By contrast, the squint eyes look quite striking with the background of green black face, making us cannot help asking ourselves what she was staring at or what she expected or scared ? Her fiery-hot body with dark background forebodes the desire for evolution.

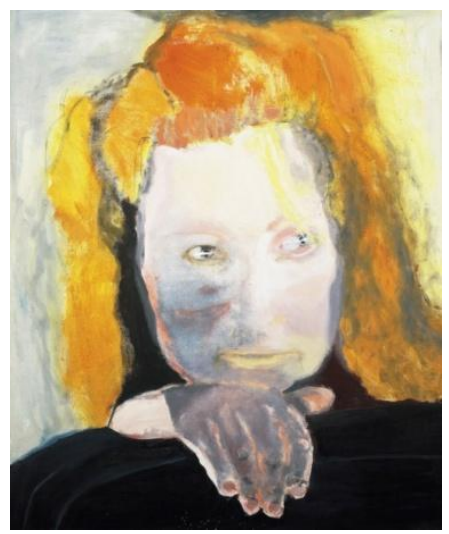

Fig. 13. The Evil Mediocrity, Marlene Dumas 1984

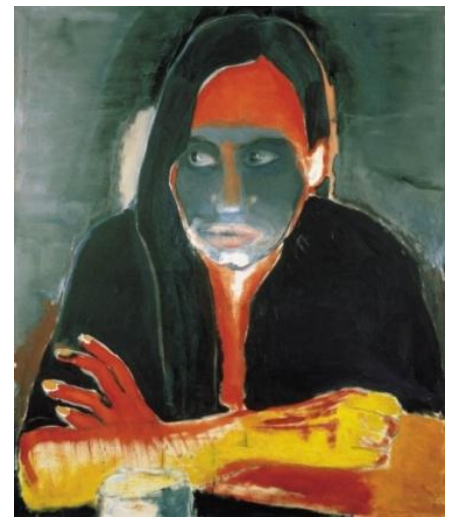

Fig. 14. The Desire for Evolution, Marlene Dumas 1984

Luc Tuymans starts to depict the potential violence in The Silent Music "Fig. 15", expressing that the violence cannot be followed while the violence is everywhere. The room with the color of is pink and blue, which is typical children color, is made for children by adults, building on the nothingness and silence. This kind of invisible control occurs at unaware childhood and the potential violence actions appear under the unfathomable surface of Tuymans arts. In the Gas Chamber "Fig. 16", there is a weird and harmful space constructed by the disorder deep stains on the wall and feces color stripe floor of the empty space, the usage of feces-like color makes the painting tone having a strong physical characteristic, also the dim room remember viewer of sense of fear of slaughter in gas chamber. Tuymans declared that "the hidden thing is the final solution, which I wish to blend in culture discourse. It can be taken as a metaphor of culture we exist in, and I think it could be a possibility that might occur again."

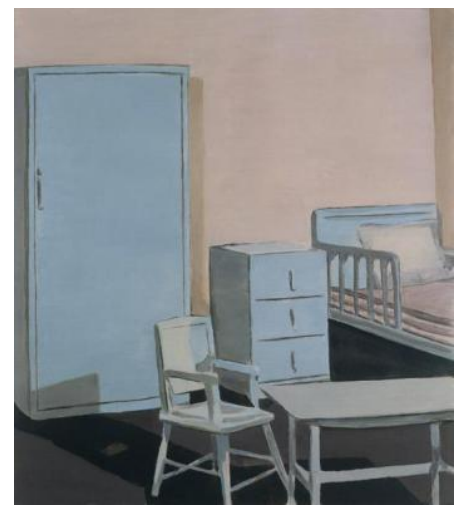

Fig. 15. The Silent Music, Luc Tuymans 1993

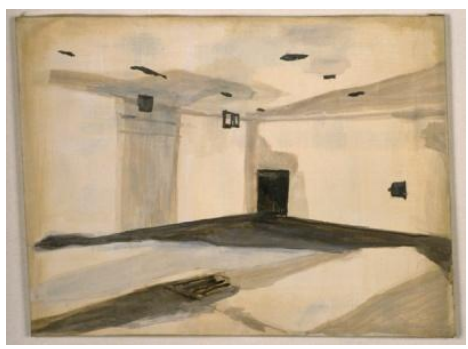

Fig. 16. Gas Chamber, Luc Tuymans 1986 
The Break uses a method of dealing windy "Fig. 17", depicting the process of transferring form into inform as a cloud of dust. The depicting of theme is contrast to traditional painting, which has no center but rolling action, confusing viewers to make sure the dimensional orientation of the case or determine the viewers own relative location. The only thread is the street lamp on the bottom left which is equivocal content as well. Some of the viewers read the Break as the destroyed scene of world trade center of USA, due to the silent collapsed setting is weird and acquainted. This work does not use the strong visual effect of the breaking process but transfers the effective impetus of emotion conflict to the outside of the painting.

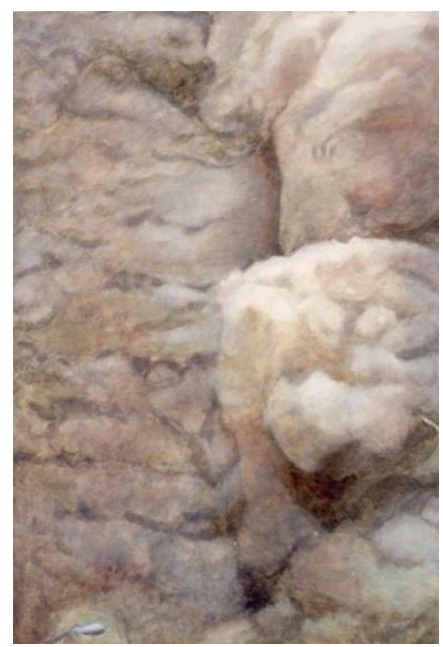

Fig. 17. Break, Luc Tuymans 2005

Ghenie's work has a fierce politic metaphor, the guilt of grievous massacre made by Hitler will undoubtedly be engraved in human history. The painter constantly recreates the image of Hitler and his wife Eva Braun, the scene of the Pie Fight Exercise 18/2/12 chose the office of the presidential palace of Hitler's new empire of 1939 "Fig. 18" "Fig. 19", which became the decision place where Hitler making various criminal activities. This work depicts the moment that Hitler sitting on the couch with his head turning round at viewers, the blade coating of chairs and his face is similar to Francis Bacon's depicting to the Screaming Pope.

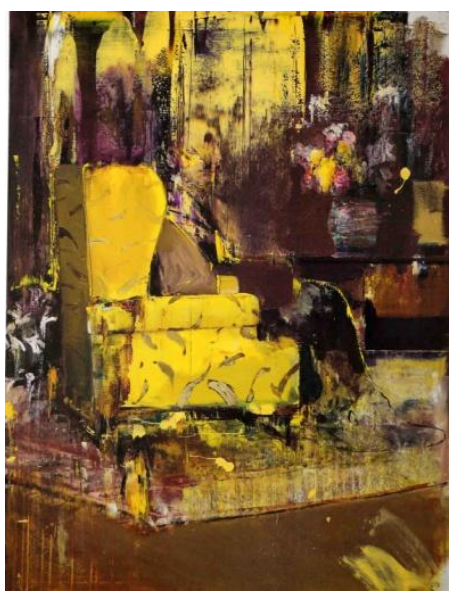

Fig. 18. Pie Fight Exercise 18/2/12, Adrian Ghenie 2012

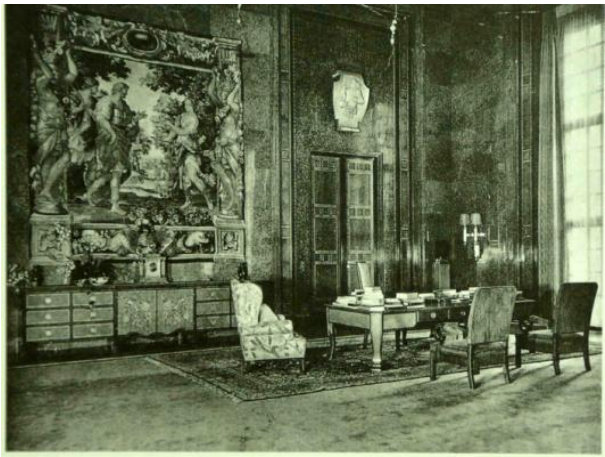

Fig. 19. Hitler's Office, Premier House of the New Empire 1939

The metaphor of diseases is frequently quoted to politics philosophy. Base on the metaphor of political inner infection, Shakespeare invents lot of source domains of metaphors, like contagion, infection and tumor. Taking special diseases as sample of normal diseases, and any disease has no own unique logic. Along with the attention to modern society political problem, the modern artists successively quote metaphor of diseases, to get involved in the attention of real political case and social problem. The artists transfer the metaphor of diseases with politic philosophy in vision and conduct destruction and reconstitution of a large amount of visual pictures produced by the society of spectacle; hence, they can make clear of the political intention in spectacle pictures, make the real world reappear.

\section{MODERNITY DISEASES}

Here and now, human face more and more disasters and crisis. The anti-limiting population increasing of world poverty-stricken area, constantly emerging nuclear power plant leakage case, intensifying tresis and wastage of ozone sphere, destruction of ecotope, successively conflict between super countries and the frequently occurring of worldwide economic crisis etc. hence, the metaphor of diseases is taken to express the anxiety to the order of society and health per se become a rather controversial topic. Before the city is taken as a carcinogenic environment, it per se has already been taken as cancer, which is a abnormal, inorganic growth place and a full of squander, greed, passion place. Moreover, the modern city leads to a large amount of creations of noisy, chaotic and scrolling city image. Sontag declares that, "once production and consumption become one of the society main activities, this society has already become 'modern"'. In addition, industrial society brings people the sense of alienation and bewilderment. People in modern city almost construct their identity by consuming products; unconsciously people in consumption society have the mental disease of "commodity fetishism".

In the large amount of works of Dumars, the diseases metaphor of modernity is profound and direct. The works We Believe in God (pay to the ferryman) intensively depicts the closed eyelid of figures "Fig. 20", which is reminiscence to a rite of ancient Greek, as put the coins on the eyes of the death is for payment to ferryman, making the death ride out of the Styx and reach the death world. It makes us have to remind of the US idol Marilyn Monroe that the words "we believe in god" are taken as a motto printed on the side of dollars. 
Tuymans chose an autopsy picture of Monroe from a biography of her instead of the sexy and charming image of her in the Dead Monroe "Fig. 21". It is a side face feature of Monroe with nearly only the color of blue and white, sufficiently exhibiting Monroe's dead moment without vital sign. In the picture, her skin is no more beautiful but with stains and festers. She is no more the image of American sexy goddess but is a normal person who left with sadness and disappointment. The beautiful myth created by modern society turns to decay and ruins hastily.

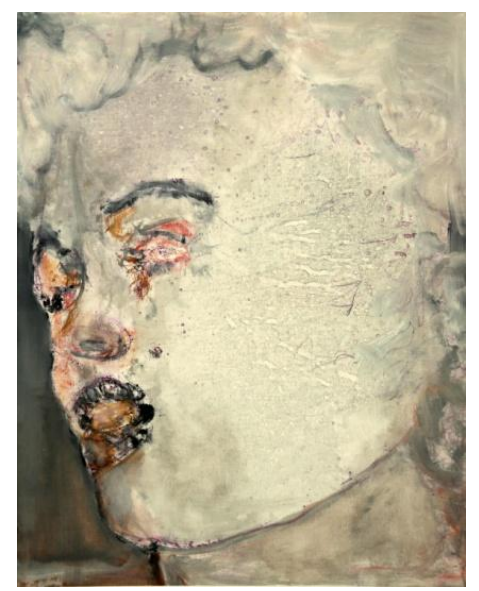

Fig. 20. We believe in God, Marlene Dumas 2008

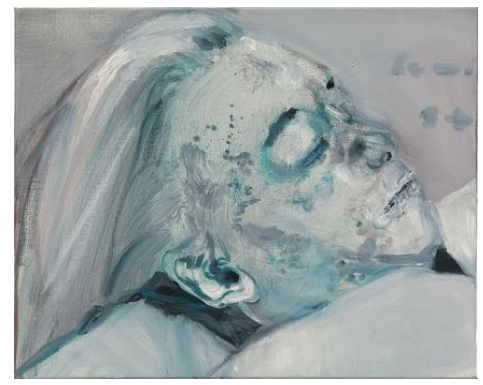

Fig. 21. The dead Monroe, Marlene Dumas 2008

Baudrillard's theory on modern city vista is more a starting-point of awareness than only a warning. The time, vista and people are all disappearing little by little as the scene and there is nearly no more space for public activities. The ad, which have permeated into every field, could turn various dirty things into actual and specific products, hence it becomes the one and only landscape for living that people's life are full of omnipresent advertisements. Atom, particle and molecule are shining and moving in all kinds of huge display screens, the real landscape and space of public activities has gone.

The works Destiny depicts the fashion models in the window of shops beside the street in night "Fig. 22", the large scale of canvas is just like the real window. The dark and washed-out light ray on the shadow and glasses emphasize the ghost-like form of the models in shop and the models looks like scattering puppets looming in the gray optical haze. This works present Benjamin's description on "the rover" and "the arcade". The shop window, by traditional meaning, is symbol of visual consumption and desire, while this moment the picture fluctuates between consistency and fuzziness, making our desire for snooping motivated and defeated. The works Pharmacy depicts the acquainted objects in our daily life "Fig. 23 ", taking the shadow of the green pharmacy which can be seen everywhere at streets all over the European cities as photo materials, and people in city would not notice the common marks, the green shadow substantially replace the lack of theme. On the desert street, the landscape of commercial city ward off the symbol of the pharmacy, resolving and melting its remedy function into shapes and colors, undoubtedly we see Tuymans's spiritual dimension in the work Pharmacy.

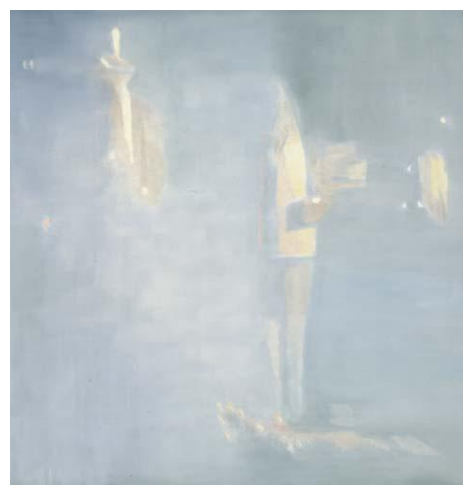

Fig. 22. Destiny, Luc Tuymans 2003

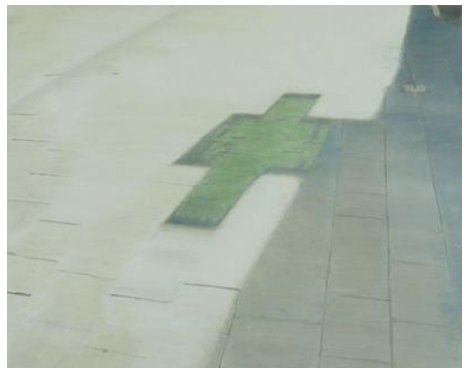

Fig. 23. Pharmacy, Luc Tuymans 2003

In German artist Daniel Richter's works, we see his profound egersis and introspection. The particoloured geometric pattern in Theory of Color represents the extremely status of prosperous modernity, under the background above "Fig. 24", a person worn clown's clothing would die with pale face and deep-set obit, broken clothes and loss and painful look, which seems to declare a finality of prosperous and grand performance. Nothing quotes the colorful gridding pattern again under background of which is playing a weird and hair-raising dance "Fig. 25",. The white skeleton twines and embraces a biology with blue wings fully growing on its substrate. On the left side of the picture, there is a black crow, which could forebode the arrival of the death of blue biology, fly towards to the twisted image with a "sandglass" in its beak. This is none other than the prediction that the modernity "sandglass" will be empty, mentioned by Kierkegaard. The man with a peaked cap in the Pointing to Punktum is surrounded by bright white light, he drops from skies with his hand point to far away "Fig. 26", surrounded by a crowd of red color people, which seems that the man is an image of savior. The red crowd emerge an extremely status of fanaticism and morbidity. 


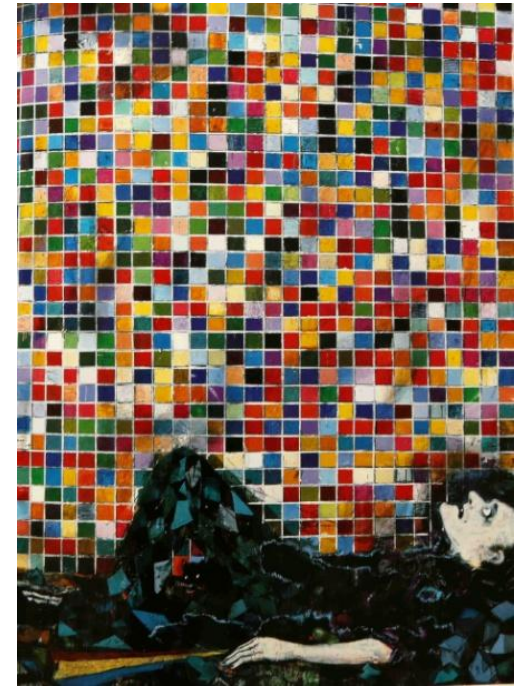

Fig. 24. Theory of color, Daniel Richter 2005

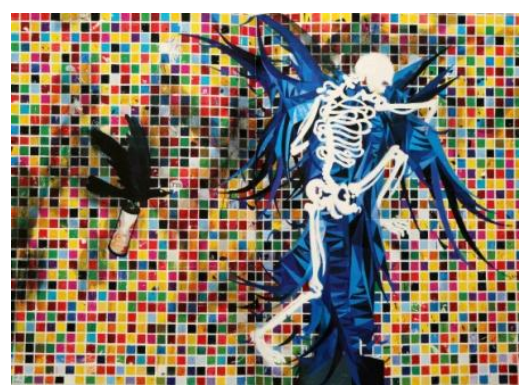

Fig. 25. Nothing, Daniel Richter 2006-2007

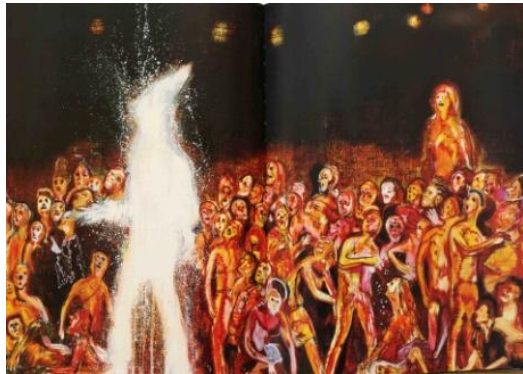

Fig. 26. Pointing to Punktum, Daniel Richter 2003

There is an everlasting modern story: the catastrophe approaches indistinctly, nothing seems to happen. The increasing reality of catastrophe makes the rhetoric of it expand unceasingly. It is still approaching. As if we are living in the twinge of catastrophe that the guided missiles, the amount of which can surround the whole earth, has not launched yet, or they could have destroyed all lives on earth repeatedly. The modern life makes us be used to living with intermittent consciousness of disasters, which are inconceivable but we pay no attention to a familiar sight. The metaphor of modernity sandglass makes us profoundly feel the miserable destiny that human walks towards to disappointment and death in covert unconsciousness. Tuymans, Dumars, Daniel Richter and Adrian Ghenie artists exhibit the awkward situation as a modern through different painting languages and expressive subject matters. Modernity brings people ease lives and extremely enjoyments, but hides potential crisis. There art works attempt to exhibit the morbidity in our lives, warning people to envisage the diseases we carried with real pictures.

\section{REFERENCES}

[1] Susan Sontag, Metaphor of Illness [M], translated by Cheng Wei, Shanghai: Shanghai Translation Publishing House, 2014, P3.

[2] Josef Helfenstein, “The Drawing, Raw Material, and Basic illustation an of the Work: An Interview with Luc Tuymans, " in Luc Tuymans : Premonition, Zeichnungen / Drawings, by Helfenstein et al. (Bern : Kunstmuse um Bern and Benteli Verlag,1997), P55.

[3] "Juan Vicente Aliaga in Conversation with Luc Tuymans," in luc Tuymans, by Ulrich Loock et al. (London: Phaidon, 1996 ),P25.

[4] Written byWalter Benjamin, One-way Street[M]. translated by Wangyong, Nanjing: Yilin Publishing Hous, 2012, P19 